\title{
Erratum to: How long do top scientists maintain their stardom? An analysis by region, gender and discipline: evidence from Italy
}

\author{
Giovanni Abramo' ${ }^{1}$ Ciriaco Andrea D’Angelo ${ }^{2,3}$. \\ Anastasiia Soldatenkova ${ }^{2}$
}

Published online: 1 February 2017

(C) Akadémiai Kiadó, Budapest, Hungary 2017

\section{Erratum to: Scientometrics \\ DOI 10.1007/s11192-016-2193-x}

In the original publication of the article, in Results section, two data in the paragraph starting from "Given that the competitions for..." have been published incorrectly: 90 (11\%) should read as $54(7 \%)$ and $60(12 \%)$ should read as $25(4 \%)$.

The correct version of the two sentences involved is provided below.

In fact, we find that 39 (24\%) of the 165 three-period TS Assistant Professors were never promoted, while 54 (7\%) three-period UN Assistant Professors were advanced to Associate Professor. Similarly, 121 (41\%) of the three-period TS Associate Professors were never promoted, while 25 (4\%) of three-period UN Associate Professors did advance to full professorship.

The online version of the original article can be found under doi:10.1007/s11192-016-2193-x.

Giovanni Abramo

giovanni.abramo@uniroma2.it

Ciriaco Andrea D’Angelo

dangelo@dii.uniroma2.it

Anastasiia Soldatenkova

anastasiia.soldatenkova@uniroma2.it

1 Laboratory for Studies in Research Evaluation, Institute for System Analysis and Computer Science (IASI-CNR), National Research Council of Italy, Via dei Taurini 19, 00185 Rome, Italy

2 Department of Engineering and Management, University of Rome "Tor Vergata", Via del Politecnico 1, 00133 Rome, Italy

3 Laboratory for Studies in Research Evaluation, Institute for System Analysis and Computer Science (IASI-CNR), Rome, Italy 